\title{
FASE LARVAL DE Spermologus rufus BOHEMAN (COLEOPTERA: CURCULIONIDAE)
}

\section{LARVAL PHASE OF Spermologus rufus BOHEMAN (COLEOPTERA: CURCULIONIDAE)}

\author{
Marliton Rocha BARRETO ${ }^{1}$ \\ Norivaldo dos ANJOS ${ }^{2}$
}

\begin{abstract}
RESUMO
Os trabalhos foram realizados no Laboratório de Entomologia Florestal da Universidade Federal de Viçosa, em Viçosa, MG, sob condições controladas $\left(t=24,9 \pm 0,9^{\circ} \mathrm{C}\right.$; UR $=78,5 \pm 5,9 \%$ ). Neste trabalho procurou-se caracterizar a fase larval da espécie Spermologus rufus e obter conhecimentos do comportamento do inseto, visando ao seu controle. Realizou-se a descrição morfológica, determinou-se a quantidade, a duração e a viabilidade dos ínstares larvais e estudou-se o comportamento alimentar e de defesa. No estudo da morfologia verificou-se que, ao eclodirem, as larvas mostravam formato subcilíndrico, pouco encurvadas e de coloração bege-clara. De acordo com os valores das larguras das cápsulas cefálicas, pode-se inferir que as larvas de $S$. rufus apresentaram três ínstares larvais. O período larval variou de 3 a 24 dias, sendo as larvas encontradas na porção interna da semente. Após a eclosão, elas permaneceram nesse mesmo local alimentandose do endosperma, até se transformarem em adultos. As larvas apresentaram fototaxia negativa.

Palavras-chave: inseto, curculionidae, morfologia, ínstar, Araucaria angustifolia.
\end{abstract}

\begin{abstract}
Works were held at Viçosa Federal University Forest Entomology laboratory, in Viçosa, MG, under controlled conditions. In this survey, larval phase of Spermologus rufus was characterized, aiming at obtaining useful knowledge to control of this insect. Quantity of larval instars, morphology description, duration and viability of instars larval, and behavior of feeding and defense were determined. It was observed in the morphologic study that after their eclosion, larvae were subcilindrical, little incurvated and with light bege colour. According to the values found, $S$. rufus larvae present three larval instars. Larval period varied from three to 24 days. The larvae were found in the internal seed portion. After eclosion, the remained in this same place, while feeding the endosperm until changed in adults. The larvae showed negative phototaxis.
\end{abstract}

Key-words: Insect, curculionidae, morphology, instar, Araucaria angustifolia.

\footnotetext{
1 Biólogo, M.Sc. CNPMS/Embrapa. Rodovia MG 424, km 65. Caixa Postal 151. Sete Lagoas, MG. CEP 35.701-970. E-mail: barreto@cnpms.embrapa.br $\equiv$ Autor para correspondência.
}

2 Eng. Florestal. Dr. Universidade Federal de Viçosa (UFV), CEP 35.570-000. Viçosa, MG. 


\section{INTRODUÇÃO}

No Brasil, a espécie Spermologus rufus foi relatada por Bondar (4) em amêndoas de cacau (Theobroma cacao L.). Das observações realizadas por esse autor resultou a hipótese de que esses insetos, provavelmente, desenvolvem-se em sementes oleaginosas de plantas silvestres da região, passando posteriormente para as sementes de cacau. As primeiras informações relacionadas à morfologia da larva de $S$. rufus foram descritas por Bondar (3). Barreto et al. (2) e Barreto (1) apresentaram informações complementares de sua biologia.

A determinação do número de ínstares larvais é importante, pois influencia diretamente no seu controle. A regra de Dyar, inicialmente usada somente para determinar o número de ínstares em lepidópteros, tem sido adotada para outras ordens, tais como Archaeognatha, Coleoptera e Hemiptera (16). Segundo Lara (12), embora esta regra venha sendo largamente utilizada, ela não se aplica a certos grupos de insetos, fato este corroborado por Parra e Haddad (16).

O controle de uma praga deve ser baseado no conhecimento de sua biologia dentro do ecossistema em que vive. Entretanto, após a realização da revisão do conhecimento sobre $S$. rufus, constatou-se um limitado número de informações sobre a biologia da espécie. Portanto, o objetivo deste trabalho foi caracterizar a fase larval da espécie $S$. rufus, com o propósito de gerar subsídios para desenvolvimento e aplicação de medidas adequadas para o controle deste inseto.

\section{METODOLOGIA}

Os trabalhos foram realizados no Laboratório de Entomologia Florestal da Universidade Federal de Viçosa, em Viçosa, MG, em condições de temperatura média aproximada de $24,9 \pm 0,9^{\circ} \mathrm{C}$ (mínima de $23,0^{\circ} \mathrm{C}$ e máxima de $26,5^{\circ} \mathrm{C}$ ), umidade relativa aproximada de $78,5 \pm 5,9 \%$ (mínima de $69,0 \%$ e máxima de $90,0 \%$ ) e fotofase de $12 \mathrm{~h}$. As sementes utilizadas apresentavam $37,0 \%$ de umidade, determinada por meio do método-padrão da estufa, utilizando-se temperatura constante de $105^{\circ} \mathrm{C}$ por $24 \mathrm{~h}(5)$.

Adultos sexados e divididos em vinte casais foram colocados em frascos de Wheaton $(60 \mathrm{ml})$ com tampa de pressão perfurada, contendo três sementes de Araucaria angustifolia, que serviram de substrato alimentar e de oviposição. Essa quantidade de sementes foi definida em função da necessidade de oferecer opções de substrato para oviposição à fêmea e do volume dos frascos.
As sementes eram trocadas diariamente. Aquelas com evidências de posturas eram transferidas para potes de acrílico. Sementes ovipositadas foram dissecadas diariamente, visando acompanhar o desenvolvimento e descrever as fases larvais do inseto, segundo metodologias de Peterson (18), Costa et al. (7) e Stehr (25). A determinação do comprimento e da maior largura de 150 larvas foi realizada por meio de medições (Figura 1), utilizando-se ocular micrométrica adaptada a microscópio estereoscópico. Os insetos foram observados desde a fase de ovo até a emergência dos adultos.

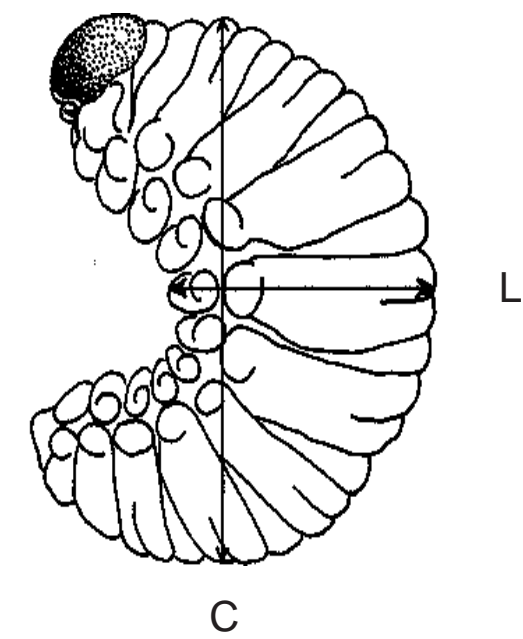

FIGURA 1 - Detalhes de comprimento (C) e maior largura (L) em larva de Spermologus rufus Boheman. Viçosa, MG, 1997.

O número de ínstares larvais foi determinado seguindo metodologias preconizadas por Dyar (9) e Parra e Haddad (16). Para a medição da maior largura das 500 cápsulas cefálicas utilizou-se ocular micrométrica adaptada a microscópio estereoscópico. As cápsulas cefálicas obtidas das dissecações diárias das sementes foram fixadas em líquido de Carnoy e conservadas em álcool 70\% (10), para posterior análise.

A duração mínima do primeiro estádio larval foi determinada com base no período decorrido entre a constatação da primeira larva no primeiro ínstar e o surgimento da primeira larva no segundo ínstar. A duração máxima foi obtida com base no período decorrido entre a data de verificação da primeira larva no primeiro ínstar e a última constatação da presença de larvas neste mesmo ínstar. Foi utilizado o mesmo procedimento para obter os estádios posteriores. A duração de cada um dos estádios foi determinada usando-se 150 larvas obtidas nas dissecações diárias.

A viabilidade de cada ínstar larval foi determinada com base na diferença obtida entre a 
quantidade total de ovos depositados e o percentual de larvas mortas, divididos pela soma da quantidade total de larvas, pupas e adultos que foram constatados nas dissecações das sementes.

Foram considerados como ovos inviáveis, ou onde não houve eclosão, aqueles em que se constatou a presença de fungos e os colocados em locais impróprios para o desenvolvimento. Alguns ovos, inicialmente observados, não foram encontrados no decorrer das dissecações, sendo por isso, desconsiderados.

As características dos comportamentos alimentar e de defesa foram descritas com base nas observações diretas, em 50 indivíduos, observados quanto ao modo de alimentação e quanto às reações comportamentais apresentadas.

\section{RESULTADOS E DISCUSSÃO}

\section{Descrição, duração e viabilidade das larvas}

No primeiro ínstar, as larvas são subcilíndricas, pouco encurvadas e de coloração bege-clara semelhante à do ovo que a originou. Seus 13 segmentos são distintos e os nove pares de espiráculos são de difícil visualização. A coloração da cabeça é marrom-claro, a das mandíbulas, marrom-escuro. A coloração, a quantidade de segmentos e o comprimento do corpo obtidos com larvas do primeiro ínstar, em S. rufus, são semelhantes, de modo geral, à morfologia descrita para o tipo de larva curculioniforme (18 e 7). O comprimento médio e a maior largura média do corpo são iguais a 1,36+0,3 mm (mínimo de
0,76 mm e máximo de 2,04 mm) e 0,69+0,19 mm (mínimo de 0,29 mm e máximo de 1,23 mm), respectivamente. A duração mínima deste ínstar foi de dois dias e a máxima de oito dias e a maior freqüência de eclosão ocorreu no quinto dia após a oviposição (Figura 2). A duração média de cinco dias no primeiro ínstar larval, obtida com S. rufus, é semelhante à observada em outros curculionídeos $(8,28)$.

Observa-se, também na Figura 2, que é pequena a quantidade de dias necessária para o desenvolvimento do primeiro ínstar larval de $S$. rufus. Isso pode ser resultante da baixa atividade alimentar das larvas, pois estas, provavelmente, ainda continham reservas alimentares provenientes da fase embrionária, uma vez que esse alimento, sendo de boa qualidade, provavelmente proporciona melhor conversão alimentar com menor gasto de energia, facilitando a mudança de ínstar.

Observa-se, também, que a viabilidade média de larvas do primeiro ínstar, obtida por casais, foi de $99,01 \pm 1,05 \%$ (mínima de $96,61 \%$ e máxima de $100,00 \%)$.

No segundo ínstar as larvas são subcilíndricas, pouco encurvadas e de coloração bege-claro, semelhante à do primeiro ínstar. Nesse período, os 13 segmentos e os nove pares de espiráculos são melhor visualizados. Comparandose com o primeiro ínstar, as colorações da cabeça e das mandíbulas não se alteraram.

Os comprimento e maior largura médios do corpo são iguais a 2,61 $\pm 0,43 \mathrm{~mm}$ (mínimo de $1,64 \mathrm{~mm}$ e máximo de 3,29 $\mathrm{mm}$ ) e a 1,35 $0,43 \mathrm{~mm}$ (mínima de 0,83 mm e máxima de 1,77 mm), respectivamente. Nesse ínstar a viabilidade média foi igual a 97,65 $\pm 1,72 \%$ (mínima de 94,34\% e máxima de 100\%).

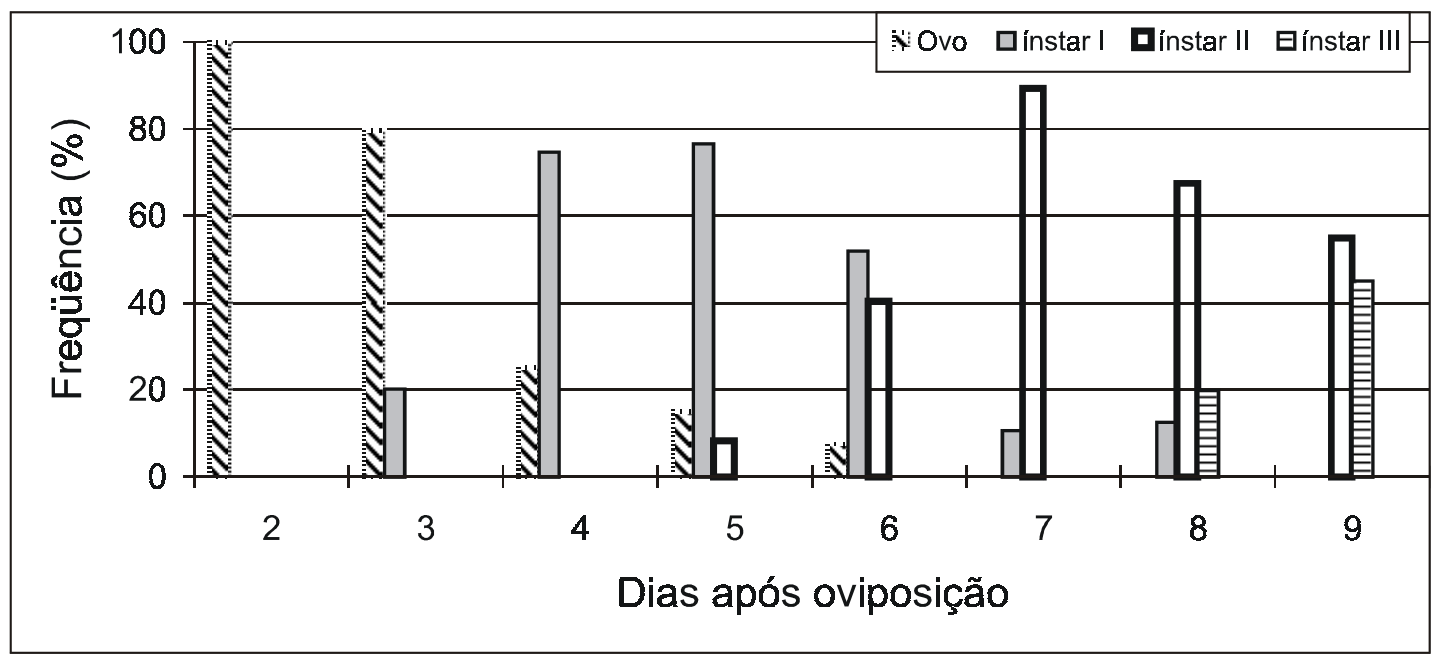

FIGURA 2 - Freqüência de insetos, segundo a fase biológica, com vistas a determinar os períodos mínimo e máximo do primeiro ínstar larval em Spermologus rufus a partir da oviposição ( $T=24,95 \pm 0,91^{\circ} \mathrm{C}, \mathrm{UR}=78,5 \pm 5,9 \%$ e fotofase $\left.=12 \mathrm{~h}\right)$. Viçosa, MG, 1997. 
A duração mínima do segundo ínstar foi de quatro dias e a máxima, de 12 dias (Figura 3), ocorrendo a maior freqüência de mudança de ínstar aos sete dias após a oviposição.

No terceiro ínstar as características morfológicas das larvas são mais visíveis, possibilitando a comparação com as dos ínstares anteriores. Observaram-se os nove pares de espiráculos e as setas presentes em volta do corpo das larvas. A cabeça das larvas, de coloração marrom-claro, é do tipo hipognata, apresentando suturas epicranial e frontal, assim como endocarena. O labium e o clípeo possuem três e dois pares de setas, respectivamente, e as mandíbulas e maxilas apresentam apenas um par de setas cada uma. As larvas ápodas e os espiráculos torácicos estão localizados na membrana posterior do protórax. O abdome possui dez segmentos, sendo que os oito primeiros apresentam um par de espiráculos e são subdivididos em epipleura, pleura e área pedal. O nono segmento não apresenta estas subdivisões e o décimo é reduzido a um lobo anal. Esses detalhes são semelhantes aos de outras descrições realizadas desta mesma espécie como as de Bondar (4), que, no entanto, relatou que o abdome da larva era desprovido de setas. Essa diferença, porém, pode ser atribuída aos equipamentos utilizados.

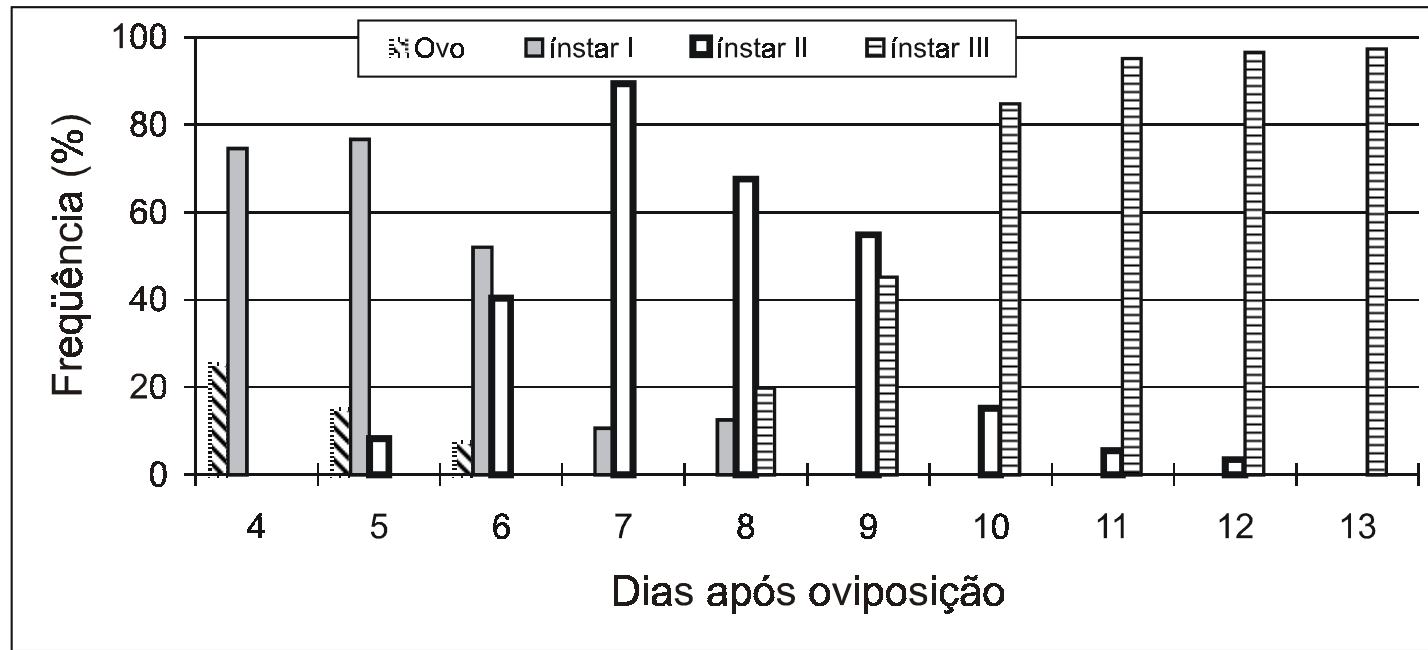

FIGURA 3 - Freqüência de insetos, segundo a fase biológica, com vistas a determinar os períodos mínimo e máximo do segundo ínstar larval em Spermologus rufus a partir da oviposição ( $T=24,95 \pm 0,91^{\circ} \mathrm{C}, \mathrm{UR}=78,5 \pm 5,9 \%$ e fotofase = $12 \mathrm{~h}$ ). Viçosa, MG, 1997.

Pelas observações realizadas, constatou-se que as larvas do terceiro ínstar apresentaram comprimento médio e largura média do corpo iguais a $5,03 \pm 1,21 \mathrm{~mm}$ (mínimo de $2,49 \mathrm{~mm}$ e máximo de $7,94 \mathrm{~mm}$ ) e 2,48+0,57 mm (mínimo de $1,16 \mathrm{~mm}$ e máximo de $3,62 \mathrm{~mm}$ ), respectivamente. Comparando-se com o comprimento das larvas nos ínstares anteriores, a larva do terceiro ínstar apresentou-se 3,7 vezes maior que a do primeiro ínstar e 1,9 vez maior que a do segundo ínstar.

As dimensões médias obtidas nas larvas de S. rufus diferiram das encontradas por Bondar (4) nessa mesma espécie, entretanto, essa diferença é atribuída, possivelmente, à metodologia utilizada pelo autor para realização das medições ou ao fato de terem sido utilizadas sementes de cacau como substrato alimentício.

O terceiro ínstar teve duração mínima de sete dias e máxima de 24 dias. A maior freqüência de eclosão ocorreu do $11^{\circ}$ ao $16^{\circ}$ dias após a oviposição (Figura 4). A longa duração do terceiro ínstar pode estar associada à maior necessidade que as larvas deste período têm de alimentação e de armazenagem de reservas nutricionais para serem consumidas na fase de pupa $(11,6)$.

A duração do terceiro período larval, obtida em $S$. rufus, foi semelhante à do curculionídeo Sphenophorus mimelus, que apresentou uma variação média de 12 dias (14). As primeiras pupas surgiram no $13^{\circ}$ dia após a oviposição, o que representa um curto período larval quando comparado com outros resultados obtidos por Bondar (4). Mas, como já foi dito, este autor utilizou como substrato alimentar sementes de cacau, o que, possivelmente, já é suficiente para alterar os resultados $(11,27)$. 


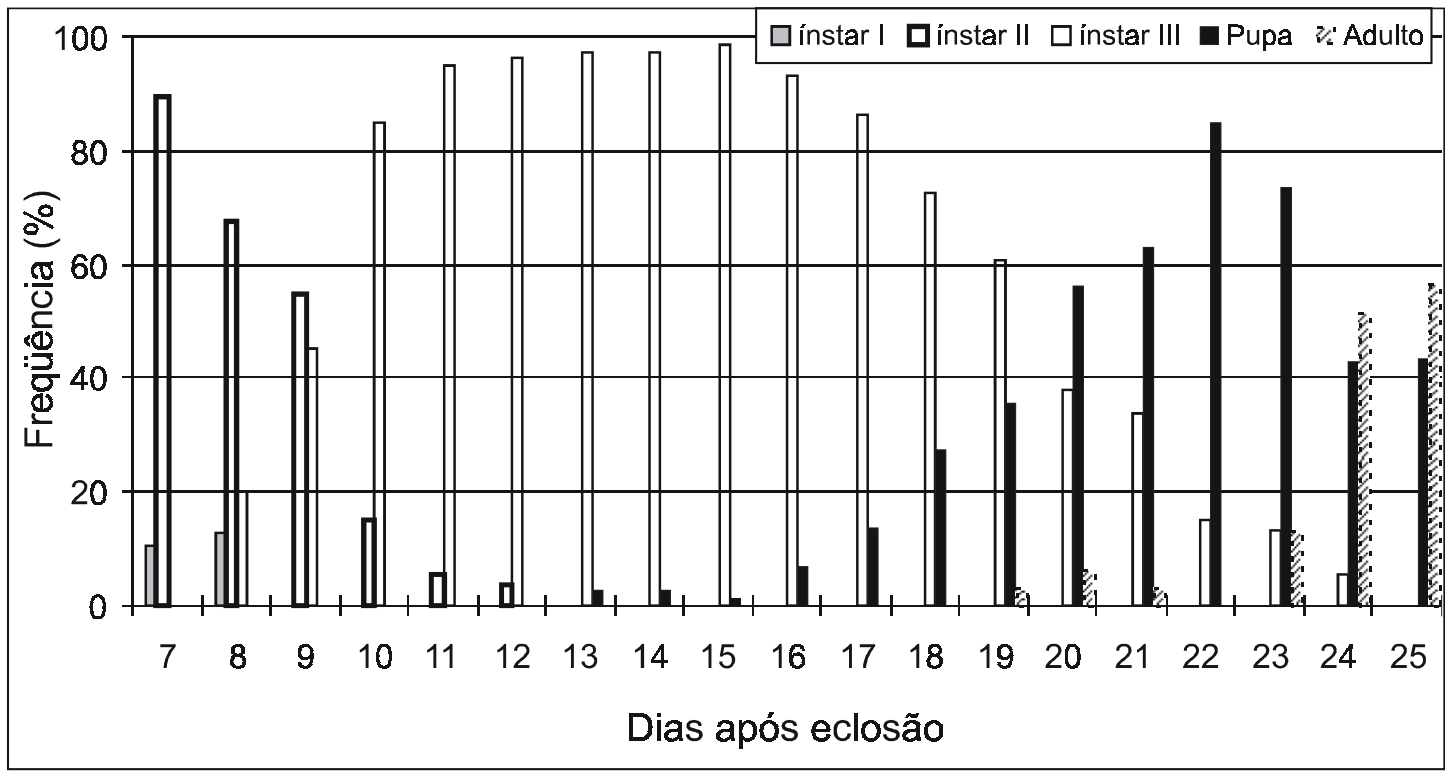

FIGURA 4 - Freqüência de insetos, segundo a fase biológica, com vistas a determinar os períodos mínimo e máximo do terceiro ínstar larval em Spermologus rufus a partir da oviposição ( $T=24,95 \pm 0,91^{\circ} \mathrm{C}, \mathrm{UR}=78,5 \pm 5,9 \%$ e fotofase $=12 \mathrm{~h}$ ). Viçosa, MG, 1997.

A viabilidade média do terceiro ínstar foi de 95,57+2,58\% (mínimo de $90,32 \%$ e máximo de $100 \%$ ). A diminuição média na viabilidade foi igual a $1,36 \%, 2,09 \%$ e $3,45 \%$, respectivamente do primeiro para o segundo ínstar, do segundo para o terceiro e do primeiro para o terceiro. Esses resultados permitem inferir sobre a qualidade da semente que serviu de alimento e substrato (24) e a necessidade de espaço mínimo para o desenvolvimento larval adequado. Segundo Santos et al. (20), se duas ou mais larvas do bruquídeo Merobruchus paquetae (Kingsolver, 1980) desenvolverem-se numa mesma semente, os insetos poderão ser mais fracos ou menos desenvolvidos que aqueles que se encontravam individualizados.

\section{Ínstares larvais}

Após a medição das cápsulas cefálicas e a ordenação dos dados segundo as suas freqüências, construiu-se a curva multimodal mostrada na Figura 5. O pequeno intervalo de variação da largura de cápsula cefálica do primeiro ínstar pode indicar uma estreita relação com as dimensões dos ovos que as continham (23). O aumento gradativo dos intervalos nos ínstares posteriores sugere que outros fatores, como competição por alimento (15, 20), podem influenciar o crescimento larval e, conseqüentemente, aumentar o intervalo de variação da largura de cápsula cefálica dos ínstares subseqüentes.

Na curva multimodal podem ser constatados os três picos mais evidentes, tendo sido testada a hipótese da existência de três ou quatro ínstares por meio do método dos quadrados mínimos (16), obtendo-se os dados apresentados na Tabela 1. O coeficiente de determinação $\left(R^{2}\right)$ para três ínstares representou o melhor ajuste dos dados, segundo Parra e Haddad (16). Sendo assim, de acordo com os valores encontrados, pode-se inferir que as larvas de $S$. rufus apresentaram três ínstares larvais, caracterizados pelos intervalos de largura entre $0,44 \mathrm{~mm}$ e $0,63 \mathrm{~mm}$, como sendo o primeiro, $0,67 \mathrm{~mm}$ e $0,95 \mathrm{~mm}$, o segundo, e $1,04 \mathrm{~mm}$ e $1,46 \mathrm{~mm}$, o terceiro e último ínstar. A quantidade de ínstares larvais encontrada na espécie $S$. rufus foi igual à obtida nos curculionídeos Anthonomus grandis Boheman e $S$. mimelus $(14,17)$, respectivamente.

Como S. rufus ataca sementes armazenadas de cacau (22), é possível que seu ciclo de vida seja mais curto em relação a outros curculionídeos, à semelhança do que ocorre em pragas de grãos armazenados e em insetos que encontram abundância de alimento (27). Nesse caso, a metamorfose ocorre mais rapidamente.

\section{Comportamentos alimentar e de defesa}

As larvas, após a eclosão, foram encontradas na porção interna da semente e permaneceram nesse mesmo local, onde se alimentaram do endosperma até a transformação em adultos. Algumas larvas utilizavam as mandíbulas para escavar túneis e migrar em direção à porção mais interna da semente, chegando a alcançar o cotilédone. Esses detalhes confirmam os resultados obtidos por Bondar (4), quando larvas de S. rufus 
foram alimentadas com sementes de cacau. As larvas de coleópteros, ao se alimentarem do cotilédone, o danificam e impedem a germinação da semente $(26,13)$. Ainda, ao escavarem os túneis, provocam o surgimento de detritos que, associados às fezes, podem conferir sabor e odor desagra- dáveis às sementes, inutilizando-as para fins alimentícios (27).

Os túneis feitos por larvas de $S$. rufus apresentaram formato circular, em corte transversal, com suas dimensões proporcionais à largura apresentada pelas larvas em seus diversos períodos.

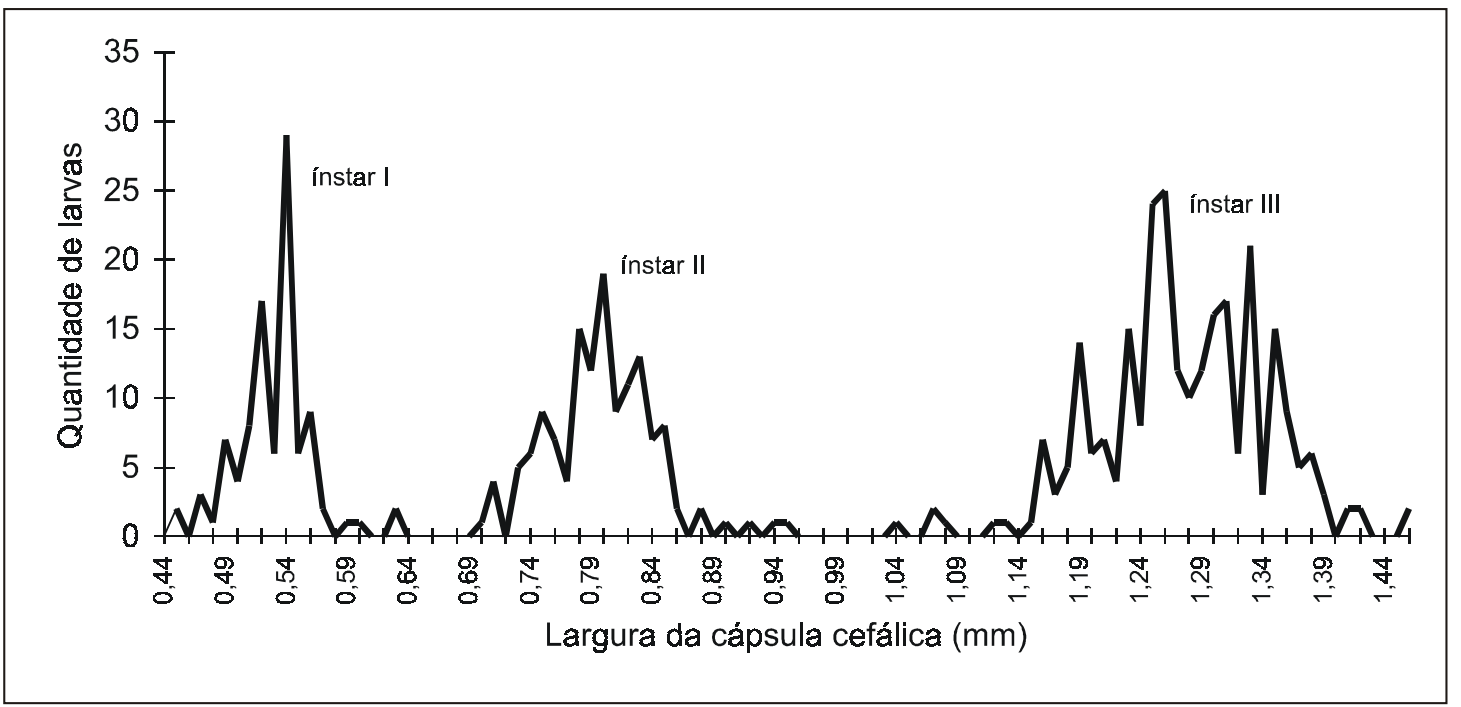

FIGURA 5 - Curva multimodal de freqüência das larguras das cápsulas cefálicas de larvas de Spermologus rufus. ( $T=24,95 \pm 0,91^{\circ} \mathrm{C}, \mathrm{UR}=78,5 \pm 5,9 \%$ e fotofase $\left.=12 \mathrm{~h}\right)$. Viçosa, MG. 1997.

TABELA 1 - Intervalo (I) de largura de cápsula cefálica $(\mathrm{mm})$, razão de crescimento $(\mathrm{K})$ e coeficiente de determinação $\left(\mathrm{R}^{2}\right)$ estimados para três e quatro ínstares larvais de Spermologus rufus $\left(T=24,95 \pm 0,911^{\circ} \mathrm{C}, \mathrm{UR}=78,5 \pm 5,9 \%\right.$ e fotofase $=12 \mathrm{~h}$ ). Viçosa, MG, 1997

\begin{tabular}{cccc}
\hline Número de instares & $\mathrm{I}$ & $\mathrm{K}$ & $\mathrm{R}^{2}$ \\
\hline & $0,44-0,63$ & & 0,98 \\
& $0,67-0,95$ & 1,57 & \\
\hline & $1,04-1,46$ & & 0,31 \\
& $0,44-0,63$ & 1,25 & \\
& $0,67-0,95$ & & \\
& $1,04-1,29$ & & \\
\hline
\end{tabular}

As larvas não apresentaram canibalismo em nenhum dos ínstares estudados, mesmo quando agrupadas sem alimento, diferenciando de resultados obtidos com outros curculionídeos $(19,20)$.

As larvas de $S$. rufus apresentaram fototaxia negativa, caracterizada pela procura de ambientes escuros, quando se encontravam fora das sementes.

A construção da câmara pupal realizada pelas larvas serve de abrigo contra inimigos naturais e evita o dessecamento. Esse tipo de comportamento também foi relatado por Bondar (4) com relação a esta mesma espécie.

\section{Empupação}

As larvas construíram a câmara pupal no interior das sementes de A. angustifolia, utilizandose da testa e do endosperma da semente e de seus 
excrementos. Essa tarefa foi realizada por meio de movimentos giratórios do próprio corpo e, em $76 \%$ das observações, as câmaras encontravam-se fixas à testa da semente. Comportamento também semelhante aquele observado por Bondar (4) ao estudar os hábitos de indivíduos da mesma espécie.

\section{REFERÊNCIAS}

1 BARRETO, M. R. Biologia de Spermologus rufus Boheman (Coleoptera: Curculionidae) em sementes de Araucaria angustifolia (Bert.) Kuntze. Viçosa: 1996. 75 f. Dissertação de mestrado - Universidade Federal de Viçosa.

2 BARRETO, M. R.; ANJOS, N.; SOUZA, M. P. Ocorrência de Spermologus rufus (Coleoptera: Curculionidae) em sementes de Araucaria angustifolia. Anais da Sociedade Entomológica do Brasil, v. 25, n. 3, p. 567-568, 1996.

3 BONDAR, G. Notas entomológicas da Bahia XII. Revista de Entomologia, v.14, p. 94-99. 1943.

4 BONDAR, G. O Cacao II - Moléstias e inimigos do cacaoeiro no Estado da Bahia, Brasil. Salvador: Imprensa Official, 1925. $126 \mathrm{p}$.

5 BRASIL. Ministério da Agricultura e Reforma Agrária. Regras para análise de sementes. Brasília: 1992.365 p.

6 CHU, H.F.; CUTKOMP, L.K. How to know the immature insects. 2 ed. Dubuque: Wm. C. Brown Comunications, 1992. $346 \mathrm{p}$.

7 COSTA, C.; VANIN, A.S.; CASARI-CHEN, S.A. Larvas de Coleoptera do Brasil. São Paulo: USP/Museu de Zoologia, 1988. 379 p.

8 CUDA, J.P.; BURKE, H.R. Reproduction and development of the Potato Stalk Borer (Coleoptera: Curculionidae), with notes on field biology. Journal of Economic Entomology, v. 79, p. 1548-1554, 1986.

9 DYAR, H.G. The number of molts of Lepidopterous larvae. Psyche. 5: 420-422. 1890.

10 GALLO, D.; NAKANO, O.; SILVEIRA NETO, S.; CARVALHO, R.P.L.; BATISTA, G.C.; BERTI FILHO, E.; PARRA, J.R.P.; ALVES, S.B. Manual de entomologia agrícola. São Paulo: Agron. Ceres, 1988. 531p.

11 HAGEN, K.S.; DADD, R.H.; REEE, J. The food of insects. In: HUFFAKER, C. B., RABB, R. L. (Eds.). Ecological Entomology. New York: John Wiley \& Sons, 1984.

12 LARA, F. M. Princípios de entomologia. Piracicaba: Livro Ceres, 1979. 340 p.

13 LINIT, M.J.; NECIBI, S. Black walnut curculio: Patterns of nut damage in a plantation environment. Agroforestry Systems, v. 29, p.321-331, 1995.

14 MORÁN, A.H.; FRÍAS, E.A.; TERÁN, A.L. et al. Cria en insectario de Sphenophorus mimelus Vaurie, 1978 (Coleoptera: Curculionidae, Rhynchophorinae), enemigo natural del "Cebolin", Cyperus rotundus L. (Cyperaceae), y caracterizacion morfologica de sus estadios larvales primero y ultimo. Revista de Investigación, v. 7, n. 1/4, p. 41-53, 1989.

15 PARRA, J.R.P. Consumo e utilização de alimentos por insetos. In: PANIZZI, A.R.; PARRA, J.R.P.; (Eds.). Ecologia nutricional de insetos e suas implicações no manejo de pragas. São Paulo: Manole, 1991. p. 9-66.

16 PARRA, J.R.P.; HADDAD, M.L. Determinação de número de ínstares dos insetos. Piracicaba: FEALQ, 1989.47 p.

17 PARROTT, W.L.; JENKINS, J.N.; BUFORD, W.T. Instars and duration on stadia of boll weevil larvae. Annals of the Entomological Society of America, v. 63, n. 5, p. 1265-1267, 1970.

18 PETERSON A. Larvae of Insects: an introduction to neartic species. 4 ed. Columbus: Edwards Brothers, 1960. 416 p.

19 SÁNCHEZ, P.A.; JAFFÉ, K.; HERNÁNDEZ, J.V. et al. Biologia y comportamiento del picudo del cocotero Rhynchophorus palmarum L. (Coleoptera: Curculionidae). Boletín de Entomología Venezoelana, v. 8, n. 1, p. 83-93, 1993.

20 SANTOS, G.P.; ANJOS, N.; ZANÚNCIO, J.C. Bionomia de Merobruchus paquetae KINGSOLVER, 1980 (Coleoptera: Bruchidae) em sementes de Albizia lebbek BENTH (Leguminosae: Mimosoidae). Revista Árvore, v. 9, n. 1, p. 87-99, 1985.

21 SHARIFI, S.; MILLS, R.B. Developmental activities and behaviour of the rice weevil inside Wheat Kernels. Journal Economic Entomology, v. 64, n. 5, p. 1114-1118, 1971.

22 SILVA, P.; BASTOS, C.A.S. Armazenagem nos trópicos com referência especial ao cacau comercial da Bahia. In: SEMINÁRIO NACIONAL DE ARMAZENAGEM, 2, 1976. Brasília. Anais... Brasília: CIBRAZEM, 1976. v. 2, p. 227.

23 SILVEIRA, R.D. Biologia de Coelomera lanio (Dalman) (Coleoptera: Chrysomelidae: Galerucinae). Viçosa: Universidade Federal de Viçosa, 1996. 80 p. Dissertação (Mestrado em entomologia) - Universidade Federal de Viçosa, 1996.

24 SLANSK JR. F.; SCRIBER, J.M. Food consumption and utilization. In: KERKUT, G.A., GILBERT, L.I. (Eds.). Comprehensive Insect Physiology Biochemistry and Pharmacology. Oxford: Pergamon Press, 1985.

25 STEHR, F.W. Immature insects. lowa: Kendall/Hunt publishing Company, 1991. v. 2, 975p.

26 TAN, Y.; HOWER, A.A. Development and feeding of clover root Curculio (Coleoptera: Curculionidae) larvae on alfafa. Environmental Entomology, v. 20, n. 4, p. 1013-1018, 1991.

27 VIÑUELA, E.; ADAN, A.; DEL ESTAL, P. et al. Plagas de los productos almacenados. Madrid: Unidad de protección de cultivos. E.T.S.I.A. Ministerio de Agricultura, Pesca y Alimentación, 1993. 31 p.

28 WEISS, R.M.; GILLOTT, C. The biology of the Lesser Clover Leaf Weevil, Hypera nigrirostris (FABR.) (Coleoptera: Curculionidae), on red clover, Trifolium pratense L., in Saskatchewan. The Canadian Entomologist, v. 125, p. 831-837, 1993. 